\title{
FORMAÇÃO INTEGRAL E INTEGRADA: UMA PERCEPÇÃO DOS DOCENTES DO CURSO DE INFORMÁTICA DO IFRN
}

\author{
M. R. G. de SOUZA; M. L. T. da SILVA'; M. S. SILVA \\ Instituto Federal de Educação, Ciência e Tecnologia do Rio Grande de Norte \\ marcela20souza@hotmail.com'; lourdes.teixeira@ifrn.edu.br²; socorro.silva@ifrn.edu.br ${ }^{3}$
}

Artigo submetido em $x x x x / 20 x x$ e aceito em $x x x x / 20 x x$

DOI: 10.15628/holos.2015.xxxx

\section{RESUMO}

Esse estudo faz parte de uma pesquisa realizada com docentes do curso de informática de três campi do Instituto Federal de Educação, Ciência e Tecnologia do Rio Grande do Norte (IFRN). O universo pesquisado compreendeu vinte e sete docentes, pertencentes aos núcleos estruturante, articulador e tecnológico, sendo nove professores por cada núcleo. Tem como objetivo identificar quais as percepções que esses docentes têm a respeito da formação integral e da formação integrada no Ensino Médio Integrado à Educação Profissional e Tecnológica (EPT). Partimos inicialmente para os estudos bibliográfico e documental que consubstanciaram o aporte teórico, à luz de autores do campo da formação de professores, formação integral e formação integrada, bem como do currículo integrado, a exemplo de Machado (2010, 2011), Ciavatta (2005), Moura (2013),
Ramos (2005, 2010), Imbernón (2011). Posteriormente nos reportamos para o campo empírico tendo como ponto norteador a análise da categoria 'percepção sobre EPT, a qual nos deu uma visão ampla da percepção dos professores sobre a formação integral e integrada e a concepção de currículo no âmbito do IFRN. Como parte conclusiva, o estudo apontou, a partir das vozes dos sujeitos entrevistados, que a grande maioria desses professores ainda não se apropriaram epistemologicamente das concepções analisadas, observamos também que tais concepções ainda não foram suficientemente compreendidas e efetivadas em suas práxis, apesar de que eles demonstraram uma intencionalidade em aceitar e adotar essas concepções em seu fazer pedagógico diário.

PALAVRAS-CHAVE: Formação docente, Formação integral e integrada, Educação profissional e Tecnológica, Currículo integrado.

\section{FORMACIÓN INTEGRAL E INTEGRADA: UNA PERCEPCIÓN DE LOS DOCENTES DEL CURSO DE INFORMÁTICA DEL IFRN}

\section{RESUMEN}

El estudio hace parte de una investigación realizada con docentes del curso de informática de tres campi del Instituto Federal de Educação, Ciência e Tecnologia do Rio Grande do Norte (IFRN). El universo de la investigación comprendió veintisiete docentes, que pertenecen a los núcleos estructurante, articulador y tecnológico, siendo nueve profesores en cada núcleo. Tiene como objetivo identificar cuáles son las percepciones que eses profesores tienen respecto a la formación integral e integrada en la enseñanza media integrada a la educación profesional (EPT). Inicialmente hicimos el estudio bibliográfico y documental, que consubstanciaron el aporte teórico, con los autores del campo de la formación de profesores y la formación integral e integrada, para ello dialogamos con Machado (2010, 2011), Ciavatta (2005), Moura (2013), Ramos (2005, 2010), Imbernón (2011). En seguida nos volvimos al campo empírico, tiendo como puntos del análisis tres categorías que hacen parte del guion de la entrevista, el instrumento de investigación, que comprenden la identidad docente, la práctica pedagógica y la percepción sobre la EPT. Elegimos la tercera categoría, la cual nos ha dado un visón amplio de las percepciones de los profesores respecto a las concepciones que en el trabajo discutimos, en el ámbito del IFRN. Concluimos que el estudio apuntó, a partir de las voces de los sujetos entrevistados, que ellos aún no se apropiaron epistemológicamente de las concepciones analizadas y observamos también que esas concepciones aún no son efectivamente comprendidas en sus praxis, pero ellos demostraron una intencionalidad en aceptar y adoptar esas concepciones en su quehacer pedagógico cotidiano.

PALABRAS-CLAVE: Currículo integrado, Educación profesional y Tecnológica, Formación docente, Formación integral e integrada. 


\section{INTRODUÇÃO}

A busca por uma formação docente que permita ao educador atuar de forma plena na Educação Profissional e Tecnológica (EPT) se constitui bandeira permanente frente aos avanços e retrocessos com que o campo tem se defrontado. A própria Lei de Diretrizes e Bases da educação brasileira pouco tem se dedicado a essa modalidade de ensino, além disso, são notórios os projetos societários em disputa e os momentos de embate político que permeiam o seu percurso histórico.

Acrescenta-se a este quadro, os desafios que têm constituído a prática docente diante da diversidade de frentes em que o professor tem que atuar, a exemplo da integração da Educação Profissional à Educação Básica na Modalidade de Educação de Jovens e Adultos (PROEJA), o ensino médio integrado, a EPT indígena e quilombola, dentre outras.

Diante disso, o objetivo geral desse estudo se constitui em apresentar a percepção sobre formação integral e integrada dos professores do curso de informática do Instituto Federal de Educação, Ciência e Tecnologia do Rio Grande do Norte (IFRN), com base na análise dos depoimentos dos sujeitos pesquisados em três campi.

Partimos inicialmente para os estudos bibliográficos e documental que consubstanciaram o aporte teórico e, posteriormente, nos reportamos para o campo empírico para a realização da entrevista roteirizada.

O universo pesquisado compreendeu vinte e sete docentes que atuam no curso de informática, distribuídos em três núcleos, sendo nove professores depor cada um destes núcleos. A estrutura curricular para o ensino médio integrado constante no PPP/IFRN - 2012, está organizada por núcleos, que se referem ao conjunto de conhecimentos que fazem parte da matriz. A saber: núcleo estruturante, núcleo articulador e núcleo tecnológico. Nesta estrutura, cada núcleo corresponde às áreas do conhecimento de formação específica e as tidas como de formação geral.

O Núcleo Estruturante corresponde a conhecimentos do ensino médio - Linguagens, Ciências Humanas, Ciências da Natureza e Matemática. O Núcleo Articulador corresponde a conhecimentos do ensino médio e da educação profissional e deve contemplar disciplinas de base científica e tecnológica, disciplinas técnicas de articulação com o núcleo estruturante e disciplinas técnicas que favoreçam as práticas interdisciplinares; além desses, o Núcleo Tecnológico corresponde a saberes da formação técnica específica, de acordo com a área profissional (INSTITUTO..., 2012).

Conforme ressaltado no Projeto Político-Pedagógico do IFRN (doravante, PPP-IFRN) "Esse modelo fundamenta-se nos referenciais que articulam os eixos tecnológicos à formação integrada". (INSTITUTO..., 2012, p. 101). O locus da pesquisa abrangeu os seguintes campi: Natal Central, Parnamirim e Natal Zona Norte.

A partir de uma abordagem dialética trazemos à baila as relações, confrontos e contextos das representações sociais que se configuram no estudo. Adotaremos a pesquisa de caráter 
qualitativo e, nesse sentido, Minayo (2004, p. 12), assevera sobre a importância da questão social, e sobre outro aspecto bastante relevante nesse tipo de pesquisa, que é o da verdade provisória e inconclusa, afirmando que a discussão crítica do conceito de "Metodologias Qualitativas" nos induz a pensá-las não como uma alternativa ideológica às abordagens quantitativas, mas a aprofundar o caráter do social e as dificuldades de construção do conhecimento que o apreendem de forma parcial e inacabada.

Justifica-se ainda a utilização do método qualitativo para o estudo, considerando tanto o objetivo proposto quanto aos resultados pretendidos. Minayo (2004, p. 134) discorre sobre a pesquisa qualitativa, enfocando a sua importância para:

(a) compreender os valores culturais e as representações de determinado grupo sobre temas específicos; (b) para compreender as relações que se dão entre atores sociais tanto no âmbito das instituições como dos movimentos sociais; (c) para avaliação das políticas públicas e sociais tanto do ponto de vista de sua formulação, aplicação técnica, como dos usuários a quem se destina.

Assim, ao pensarmos o sujeito histórico, fazedor de seu tempo e em seu contexto, trazemos as vozes dos sujeitos professores, que em seu dia a dia e com sua práxis, participam desse momento em que o Ensino Médio Integrado à Educação Profissional (EMIEP) se traduz a partir, tanto do conhecimento epistemológico das novas concepções surgidas, mas principalmente de sua aceitação e adoção no seu fazer, citamos em especial a questão da formação do sujeito integral e a integração dos conhecimentos.

Desta forma, no discurso dos sujeitos entrevistados buscamos identificar qual a percepção deles, e com base nas informações obtidas, apresentar como se constitui o perfil desses docentes em relação ao seu fazer pedagógico diário, levando-se em conta o entendimento dos mesmos em relação à questão da formação integral e integrada.

Nessa perspectiva, registramos a premissa de que ao tratar sobre a formação integral e integrada na percepção dos docentes, se faz necessário nos reportarmos ao (re)pensar quão desafiadora tem sido essa questão, sobretudo a partir do período de expansão da Rede Federal de Educação Científica e Tecnológica. Neste sentido, é mister discorrermos sobre alguns apontamentos da política de formação inicial e continuada desse corpo docente, com vistas a dar respostas para as novas necessidades que se apresentam.

Sobre os desafios que se estenderam para esses docentes, Machado $(2011$, p.690) aponta para as motivações que corroboraram com esta nova realidade e assevera que:

Este desafio, já histórico, revela-se mais crítico face à atual expansão da Rede Federal de Educação, Científica e Tecnológica a partir de 2005; às metas do Programa Nacional de Acesso ao Ensino Técnico e Emprego (PRONATEC) e Plano Nacional de Educação (PNE) 2011-2020; às novas necessidades políticopedagógicas vindas com o Programa Nacional de Integração da Educação Profissional à Educação Básica na Modalidade de Educação de Jovens e Adultos (PROEJA), o ensino médio integrado, Escola Técnica Aberta do Brasil (E-TEC), Programa Educação, Tecnologia e Profissionalização para Alunos com Necessidades Educacionais Especiais (TECNEP), EPT indígena e EPT quilombola. 
Dada a heterogeneidade da disposição nas formas de organização na educação profissional e, diante da configuração de múltiplas demandas citadas pela autora, entende-se que tais desafios somente poderão ser enfrentados a partir de políticas efetivas e permanentes de formação inicial e continuada para os professores da EPT. Entretanto, historicamente as políticas brasileiras para essa modalidade têm demostrado inconsistência sendo legisladas, na maioria das vezes, por meio de portarias e pareceres, e executada por meio de programas especiais e em excepcionalidades.

Além disso, é primordial a assunção da responsabilidade por parte dos professores que nela atuam, de forma que as concepções advindas dessa nova realidade possam ser compreendidas epistemologicamente e traduzidas em sua práxis.

Nosso arcabouço teórico se constituiu à luz de autores do campo da formação de professores, formação integral e formação integrada, bem como de currículo integrado, a exemplo de Machado (2010, 2011), Ciavatta (2005), Moura (2013), Ramos (2005, 2010), Imbernón (2011), dentre outros.

\section{A FORMAÇÃO DOCENTE PARA A EDUCAÇÃO PROFISSIONAL}

A proposta de formação de professores para a EP tem sido um debate recorrente em vários espaços de atuação da Educação. Tais debates buscam um meio de aproximar as discussões e importância da formação profissional inicial e continuada dos docentes nos aspectos didáticos-pedagógicos, políticos e da formação especifica articulados à formação humana e referenciadas em um projeto de desenvolvimento social e econômico para o país.

Neste sentido, estamos dando ênfase à necessidade de promover uma formação em EP para os docentes que atuam nesta modalidade, que comtemple os aspectos teóricosmetodológicos relacionados à formação profissional dos sujeitos inseridos neste contexto formativo. Souza (2013, p. 385-386) discorre que:

É necessário entendermos que uma política ou programa mesmo uma Política da Educação Profissional inicial e continuada para a Educação profissional, não pode ser vista como apêndice da Política Educacional, tão pouco da política de formação mais ampla, implementada no Brasil, por diferentes programas e ações da política governamental.

Esta afirmação reforça cada vez mais a necessidade de se ampliar o debate e apresentar proposições de políticas no meio acadêmico e institucional que recuperem esta lacuna e incidam em mudanças no sistema educacional quanto a formação de professores para a EPT.

Pensar uma política educacional articulada com a formação docente nos diferentes níveis e modalidades de ensino e nesta com a dimensão política e de desenvolvimento para o país, requer um esforço e articulação de vários setores e educadores nas mais diferentes etapas e abrangências. Segundo Machado (2013, p. 348), desde o início das discussões e iniciativas institucionais para o ensino profissional no país, pouca ou nenhuma foram as políticas destinadas à formação dos professores que iriam atuar nos estabelecimentos educacionais. 
Desde a criação das Escola de Aprendizes de Artes e Artífices em 1909 e da criação da Escola Normal de Artes e Ofícios Wenceslau Braz a falta de prioridade das políticas e a pouca importância destinada à formação de professores em geral e especificamente para o ensino profissional, se constituíram uma tônica no contexto educacional.

Nesse sentido, apesar de várias legislações que promoveram mudanças no ensino industrial, ensino secundário, ensino comercial e agrícola na Reforma de Gustavo Capanema e, posteriormente, a Lei de Diretrizes e Bases da Educação (LDB) 4024/61, nenhuma referência ou tratamento foi apresentado para a formação dos docentes para a Educação Profissional.

Segundo Imbernón (2013), historicamente a profissão docente teve uma complexidade na sua assunção como profissão, em virtude de ser considerada um oficio e não uma profissão. Desta forma, o debate acerca da profissionalização docente sempre foi tratado de forma genérica e desvalorizada e sem importância no âmbito educacional.

A formação necessária consistia apenas, em alguns casos, em possuir conhecimentos específicos para o exercício docente da profissão. Este debate sobre a profissionalização docente, segundo o autor, carece de mudanças no contexto educacional com concepções que promovam a alteração de velhas práticas e ações que cristalizam a formação docente como sacerdócio, como "oficio" e "vocação" e recuperem na sua materialidade o debate de um novo conceito de profissão e profissionalização docente.

Ainda para Imbernón (2013), se faz necessário compreender os conceitos que estão implícitos na concepção de formação docente, que são estabelecidos dentre os conceitos relacionados entre "Profissão", "Profissionalismo" e "Profissionalização". O mesmo destaca:

Profissão é um conceito, que, no campo das ações sociais, alude a um modo particular de exercê-la. Não é um termo cujos limites de aplicação encontram-se definidos. Ele comporta as mais variadas ocupações. Popkewtiz (1990), por sua vez, argumenta que o termo "profissão" possui significados diferentes segundo o país e que o uso do termo não supõe uma definição fixa de uma ideia universal e que, atualmente, se situa à margem de toda dimensão espacial ou temporal. 0 "profissionalismo" na docência implica uma referência à organização do trabalho dentro do sistema educativo e à dinâmica externa do mercado de trabalho. [...] nesta análise adotaremos esse conceito de profissão como processo. Deveríamos fugir da pretensão de converter o ensino em uma profissão no sentido tradicional (IMBERNÓN, 2013, p. 26).

É importante salientar que o conceito de profissionalismo e profissão são requisitos indispensáveis para a construção de novas concepções sobre o papel e a função do profissional docente na atualidade. A compreensão trazida por Imbernón acerca do debate da profissionalização docente e suas implicações no exercício profissional nos remete a entendermos a forma como a profissão docente foi concebida e constituída no cenário educacional ao longo de sua institucionalização.

Compreendida desde o início como sacerdócio no período colonial, caracterizada como "dom" e "vocação", não requeria uma valorização e formação adequada para ensinar. Adiante, no Império, se configurou como "ofício", associada à aquisição de habilidades e técnicas adquiridas no exercício da função. Mais uma vez se relegava a necessidade em formar os 
profissionais para o exercício do Magistério, partindo de uma necessidade premente para resgatar a valorização e identidade deste profissional, Imbernón (2013) afirma que precisam estar:

Identificados como uma exigência de redefinição da contribuição para a produção, como um meio para adquirir maior identidade social, como um critério de redistribuição de poder, como um processo para aumentar a qualidade produtiva, como um pressuposto para a proteção do coletivo, como um processo de constante mudança profissional, como obtenção da proteção da lei... (IMBERNÓN, 2013, p. 27).

Este debate sobre a formação docente foi recorrente durante todo o período histórico e esteve presente nos processos de mudanças nas legislações e na educação brasileira. Somente com a LDB/96 a formação de professores adquire relevância e centralidade, conforme o art. 62, que estabelece "a formação de docentes para atuar na educação básica far-se-á em nível superior, em curso de licenciatura, de graduação plena, em universidades e institutos superiores de educação [...]" (BRASIL, 1996).

Esta mudança inserida na legislação traz importante contribuição para os profissionais da área e demarca avanços significativos quanto à formação docente, que funcionou sob os ditames das decisões econômicas e políticas de cada contexto histórico. Porém, no que se refere à formação de professores para a Educação Profissional, não se teve um avanço no aspecto legal, pois os decretos, portarias e pareceres foram uma constante nas ações e programas instituídos.

Notadamente, a formação de professores para a educação profissional constitui-se um desafio e um embate permanente para formar profissionais nesta área. Constituir uma política nacional ampla, permanente e efetiva, requer esforço, organização e comprometimento de todos os segmentos e atores envolvidos nesta modalidade e no sistema educacional.

Neste cenário, é importante destacar como se constituiu a EP no Brasil. Conforme aponta Urbanetz (2012, p. 865), ela surge com um caráter assistencialista e vinculado a interesses econômicos das elites brasileiras. O autor afirma que "Particularmente no Brasil, a educação profissional se estruturou a partir das necessidades geradas pela crescente industrialização, por meio da criação das escolas de aprendizes e artífices no início do século XX e da fundação do Senai em 1942 e do Senac em 1946".

Essa realidade nos remete a compreender que o ensino industrial surge para atender a uma demanda de formação de mão de obra para o mercado de trabalho, visando atender a uma realidade econômica e política do país na época e voltada para ascensão social e política de uma classe social.

Cabe destacar que o Decreto no 2.208/97 regulamenta os artigos da nova LDB/96 no que se refere à educação profissional. E no artigo 9o define que as disciplinas do ensino técnico poderiam ser ministradas não apenas por professores, mas por instrutores e monitores, uma incúria com relação às exigências de habilitação docente. Esse decreto retrata a falta de prioridade e compromisso político e institucional com a formação docente para a educação profissional, bem como a ausência de políticas e programas que referendem políticas públicas para este segmento. 


\title{
3 A FORMAÇÃO INTEGRADA: UMA CONCEPÇÃO
}

Pretendemos refletir sobre o que é a Formação Integrada e que proposta essa formação oferece na perspectiva da EP integrada ao Ensino Médio. Na leitura de Ciavatta (2005), entendemos que o termo "integrar" tem um significado próprio em um contexto específico.

Nesse caso, integrar compreende uma integralidade, um sentido de completude que constitui a proposta pedagógica voltada para a educação geral integrada à educação profissional - nas instituições que se propõem implementar o EMI. Essa integração deve se estabelecer tanto nos processos educativos quanto nos processos de produção do trabalho, e que pode não apenas ser estabelecido no ensino médio, mas também em outros níveis e modalidades de ensino. Nessa perspectiva:

\begin{abstract}
A ideia de formação integrada sugere superar o ser humano dividido historicamente pela divisão social do trabalho entre a ação de executar e a ação de pensar, dirigir ou planejar. Trata-se de superar a redução da preparação para o trabalho ao seu aspecto operacional [...]. Como formação humana, o que se busca é garantir ao adolescente, ao jovem e ao adulto trabalhador o direito a uma formação completa para a leitura do mundo e para a atuação como cidadão pertencente a um país, integrado dignamente à sua sociedade política. (CIAVATTA, 2005, p. 85).
\end{abstract}

A formação integrada passa a ser uma proposição didático-pedagógica que possibilitará ao ser humano superar a dualidade histórica na educação brasileira e que poderá também, a partir dessa superação, agir contra-hegemonicamente na sociedade, na economia, na política. Propõe a junção do pensar e do fazer, o conhecimento e fazer técnico com o saber tecnológico, científico e cultural.

Essa formação omnilateral proporciona a todos, inclusive aos das classes menos favorecidas, uma educação plena e a possibilidade de integração ao mundo político-social, produtivo-econômico e também cultural da sociedade.

A origem do conceito de formação integrada é antiga, se constitui na "educação socialista" que almejava formar o homem omnilateralmente, isto é, em todas as suas potencialidades, nas dimensões física, intelectual, cultural, política e científico-tecnológica (CIAVATTA, 2005).

A superação da dualidade social e, consequentemente, educacional (que pretende uma educação geral, intelectual para as elites dirigentes e formação técnica, manual, instrumental para os filhos da classe trabalhadora) é um dos pontos dessa historicidade que nos auxilia em compreender a necessidade de começar a se pensar em uma formação inteira para todos.

Essa possibilidade significa engajar uma base técnico-científica e humanística bem como um preparo intelectual aos processos produtivos do trabalho possibilitando necessárias condições ao (futuro) trabalhador de participar de uma realidade menos desigual, no sentido de o aprendiz-trabalhador ter a mesma formação dos que são das elites, bem como acesso à cultura geral e aos bens produzidos socialmente que são de interesse de todos e não privilégio de poucos. Nesse sentido, Ciavatta (2005, p. 94) pondera: 
A formação integrada entre ensino geral e a educação profissional ou técnica (educação politécnica ou, talvez, tecnológica) exige que se busque os alicerces do pensamento e da produção da vida além das práticas de educação profissional e das teorias da educação propedêutica que treinam para o vestibular. Ambas são práticas operacionais e mecanicistas, e não de formação humana no seu sentido pleno.

A autora nos faz refletir sobre uma formação que ora caminha para um ensino propedêutico, que treina os estudantes apenas para adentrar na universidade, ora para um ensino profissional, que, profissionalizante, pretende apenas formar para uma profissão (de modo operacional, instrumental). Essa educação notadamente dual é em suas particularidades uma formação meramente funcional, mecânica e que não tem o interesse de humanização na educação do homem. Ao trazer o aspecto humanista para a educação, a formação integrada busca trabalhar ambas as formações (geral e profissional) de modo a promover um espaço educacional de cultura geral e cultura técnica que caminham juntas para uma formação plena do ser humano.

De acordo com Ramos (2010, p. 51-52):

O conceito de integração, entretanto, vai além da forma. Não se trata de somar os currículos e/ou as cargas horárias referentes ao ensino médio e às habilitações profissionais, mas sim de relacionar, internamente à organização curricular e do desenvolvimento do processo de ensino-aprendizagem, conhecimentos gerais e específicos; cultura e trabalho; humanismo e tecnologia. A construção dessas relações tem como mediações o trabalho, a produção do conhecimento científico e da cultura.

A integração entre formação geral e formação profissional não pode se deter apenas em articular uma a outra, ou de sobrepor as disciplinas, mas é necessário compreender o que a autora nomeia como "relação interna" entre o currículo da formação integrada e o ensinoaprendizagem que perpassam os saberes da cultura geral e os da cultura técnica com o trabalho como princípio educativo, a tecnologia e a cultura como elementos dessa formação humanizadora.

Acreditamos que a formação integrada não é um projeto ou proposição didáticopedagógica que pode ser implementado ou até mesmo imposto às escolas, aos professores, gestores e alunos, sem considerar algumas mudanças necessárias no modo político-social existente em nossa sociedade. Essas mudanças têm relação com a superação da dualidade social e educacional, dando oportunidade de uma educação geral e educação profissional universal, pública, gratuita e que não tenha a obstinação de formar para uma profissão ou para os interesses do mercado de trabalho, que vive em constantes transformações.

Essa superação também envolve promover a qualidade das escolas públicas (sua estrutura física e acervo intelectual, muitas vezes precário e inadequado) que não estão estruturadas para viver uma nova realidade educacional, de formação inteira e humanista. É necessário investimento na carreira e formação contínua dos professores (formação para EP, por exemplo) e também em salários dignos, isto é, na provisão, por parte do Estado, é claro, em condições necessárias ao exercício da profissão docente. 
Nesse sentido, professores, gestores e a comunidade externa, em coletividade, devem pensar na constituição da formação integrada, como se deve estabelecer o ensino-aprendizagem com a prática de ações didáticas integradoras entre outras ações, sempre considerando a realidade social. Daí a importância de todos: Estado, sociedade, escola, trabalhadores da educação, educandos e suas famílias ter como horizonte comum a formação integrada.

\subsection{A Concepção de Formação Integrada: o que diz o PPP do IFRN?}

A partir do embasamento teórico que norteou as concepções de formação integral e integrada neste estudo, nos reportarmos ao Projeto Político Pedagógico (PPP) do IFRN do ano de 2012 , e que se encontra vigente como ponto norteador para o ensino no IFRN no que tange ao EMIEP, encontramos concepções que reforçam a presença da formação integral e da formação integrada adotadas por este documento.

$O$ referido documento concebe a EPT, e a sua relação com o trabalho como princípio educativo, dentro de um currículo integrador que relaciona, sem hierarquização, as áreas do conhecimento humano com vistas à formação de indivíduos plenos nesse sentido. Dentre vários trechos que contém as concepções defendidas no PPP/IFRN, trazemos de forma sucinta algumas no quadro 1, a seguir:

\section{Quadro 1 - Concepções do PPP/2012 - IFRN}

\begin{tabular}{|c|c|}
\hline Concepção & Descrição no PPP/2012- IFRN \\
\hline Ser humano & Compreende o homem plural em sua constituição \\
\hline Sociedade & $\begin{array}{l}\text { Concebe os processos de ensino e de aprendizagem, numa visão crítica e } \\
\text { reflexiva, com vistas a transformação da realidade social. }\end{array}$ \\
\hline $\begin{array}{l}\text { Educação } \\
\text { Profissional e } \\
\text { Tecnológica }\end{array}$ & $\begin{array}{l}\text { Necessidade que seja implantado processo educativo com práticas mediadoras } \\
\text { e emancipatórias em consonância com o rigor científico e com a } \\
\text { omnilateralidade e as dimensões culturais, linguísticas, artísticas, sociais, } \\
\text { técnicas e tecnológicas. }\end{array}$ \\
\hline Ciência & $\begin{array}{l}\text { Em processo dialético e integrador (ciências humanas, ciências da } \\
\text { natureza...sem hierarquização }\end{array}$ \\
\hline Cultura & $\begin{array}{l}\text { Adota como princípio norteador a abordagem antropológica (que considera as } \\
\text { múltiplas dimensões da cultura humana) }\end{array}$ \\
\hline Tecnologia & Apontada como campo de abrangência de todo o ser e o fazer humano \\
\hline
\end{tabular}




\begin{tabular}{|l|l|}
\hline Trabalho & $\begin{array}{l}\text { Ter o trabalho na perspectiva da formação humana integral (educação, cultura, } \\
\text { ciência e tecnologia) }\end{array}$ \\
\hline $\begin{array}{l}\text { Currículo } \\
\text { integrado }\end{array}$ & $\begin{array}{l}\text { Prega a integração construída a partir do estabelecimento de relações entre } \\
\text { conhecimentos gerais e específicos, ao longo do processo de formação, sob os } \\
\text { eixos do trabalho, da ciência e da tecnologia. }\end{array}$ \\
\hline
\end{tabular}

Fonte: INSTITUTO FEDERAL ... (2012, p. 38-58).

À luz da representação que o quadro acima nos aponta, e cujo teor foi extraído do PPP/IFRN, fica evidenciado o direcionamento de forma reiterada para que o currículo e as práticas formadoras sejam concebidos e materializados com vistas à formação integral dos sujeitos, ancorados na formação integrada traduzida na práxis dos docentes da EP.

Notadamente, a partir dos princípios que se reportam ao trabalho como princípio educativo, à educação profissional e tecnológica numa perspectiva omnilateral e à visão de um currículo integrador sem correlação hierárquica entre as áreas do conhecimento.

\section{CURRÍCULO INTEGRADO: ALGUNS PRESSUPOSTOS PARA SUA IMPLEMENTAÇÃO}

O currículo integrado é parte da proposta pedagógica de formação integrada. Esse currículo orienta, de certa forma, a materialização do trabalho do corpo docente e discente, bem como de toda a escola no que se refere, por exemplo, às ações didático-pedagógicas integradoras.

A formação omnilateral, politécnica ou integrada tem o desafio de fazer com que os professores reconheçam e se percebam partícipes ativos nessa formação, pensando, inclusive, na elaboração e promoção do currículo escolar de forma integrada e em sua efetiva implementação.

A formação e o currículo integrados apontam para o desafio de uma educação que busca idealizar e efetivar um ensino que integra o ensino médio conjuntamente com uma educação técnica/específica (de nível médio). Nesse sentido, pretende-se, com essa sessão, discutir alguns pressupostos que auxiliarão a elaboração, planejamento, organização e sistematização da compreensão de currículo integrado.

Um primeiro pressuposto que discutiremos, à luz de Machado (2010, p. 80) nos faz ponderar que o desafio de integração perpassa “[...] propostas e projetos pedagógicos comprometidos com a articulação criativa das dimensões do fazer, do pensar, e do sentir como base de formação de personalidades críticas e transformadoras [...]". Essa proposta convida os professores que ao longo do processo educativo tornaram-se acomodados com suas práticas tradicionais de ensino, a saírem de uma zona de conforto fatídica, que contradiz a profissão docente, para um estado permanente e contínuo de trabalho colaborativo e em equipe, que se constitui, também, a partir de um currículo integrado.

Já podemos inferir que essa não é uma proposta fácil ou de facilidades, mas que requer um comprometimento maior do professor (e não só deste, mas de toda a comunidade 
escolar/acadêmica, especialmente o apoio e interesse do Estado). Porém, à medida que os bons resultados forem se estabelecendo e que os desafios e conflitos estiverem sendo superados, o currículo tornar-se-á mais prático e o professor mais hábil em sua tarefa de pensá-lo, estruturá-lo e realizá-lo. Assim, os professores precisam estar abertos às mudanças e se dispor às transformações, inclusive de postura profissional, que exigirá a proposta de currículo integrado.

Um segundo pressuposto traz a discussão de um currículo integrado também à vida do estudante, aos processos histórico-sociais, econômicos e culturais vivenciados pelos alunos, a elementos do conhecimento baseado nas suas vivências e em sua cultura que "precisam ajustarse aos conhecimentos científicos para significá-los" (MACHADO, 2010, p. 82).

No tocante a essa perspectiva e ao trabalho com os conteúdos, ou seja, o trabalho com as disciplinas de ambas as formações, a autora afirma:

Um bom ponto de partida é se perguntar sobre formas de articulação dos conhecimentos que possibilitem a geração de aprendizagens significativas [...] da evolução do trabalho cooperativo, do desenvolvimento das capacidades de todos os professores e alunos de trabalhar em equipe tendo em vista a construção de processos de ensino-aprendizagem significativos. (MACHADO, 2010, p. 82-83, grifo nosso).

Podemos, a partir disso, começar a pensar por onde, como e quando podemos fazer uma proposição pedagógica que seja integradora e que torne o diálogo mais efetivo entre as disciplinas (geral e específica) e o mundo do trabalho - dentro e fora de sala de aula.

Faz-se necessário pensar também no currículo integrado como proposta e trabalho didático-pedagógico que se concretiza por meio de uma prática docente integradora propondo um ensino-aprendizagem significativo, isto é, que dê sentido ou tenha um sentido de ser para o educando. A educação precisa ser uma atividade que dê prazer, tenha um significado para a vida e para a produção da existência do ser humano - o trabalho.

A proposta pedagógica de uma ação didática integradora discutida por Machado (2010) aponta para, num primeiro momento, entender o que precisamos integrar. Nesse sentido, a integração se dá entre as finalidades, os objetivos da escola conjuntamente à prática pedagógica e, por meio disso, deve-se pensar na dimensão integral da vida do educando, que, além de estudante, tem outros papéis importantes na sociedade em que vive.

Convém-nos compreender, a partir disso, como se dará o processo de elaboração do currículo integrado no que se refere ao conhecimento geral e ao conhecimento técnico/específico - isto é, aos conteúdos ministrados por professores da formação geral e professores da formação profissional, implicando a contemplação das disciplinas.

Ramos (2005) expõe que a sobreposição de disciplinas não pode ser considerada como fator de integração na proposta de currículo integrado, bem como a soma de mais um ano aos três anos do ensino médio, isso também não configura, de todo, formação integrada. De acordo com a autora "A integração exige que a relação entre conhecimentos gerais e específicos seja construída continuamente ao longo da formação, sob os eixos do trabalho, da ciência e da cultura." (RAMOS, 2005, p. 122). Assim, a formação do educando, na proposta ora discutida, 
precisa ser considerada no decorrer dessa formação, na prática pedagógica das disciplinas, atentando para a transversalidade dos eixos que a autora assinala.

O saber ou o conhecimento geral promovido na educação básica tem o papel importante (ou deveria ter) de proporcionar ao estudante os conhecimentos necessários à sua formação intelectual, cultural, à vida em sociedade, aspectos imprescindíveis em todas as profissões. Além de "fornecer os fundamentos para uma concepção científica da vida e contribuir para desenvolver as faculdades cognitivas e as capacidades do indivíduo." (MACHADO, 2010, p. 83). A autora contempla, ainda, o desenvolvimento da autoaprendizagem, a criatividade, a curiosidade, o espírito de inovação e a versatilidade.

No que se refere à educação profissional, a autora aponta que esta "tem seu foco fundamental nos conhecimentos tecnológicos; conteúdos que não se confundem com saberes empíricos, mas que guardam com eles relação; referências obrigatórias ao exercício de atividades técnicas e de trabalho." (MACHADO, 2010, p. 83). Ou seja, diz respeito a um conteúdo específico, mas amplo, também científico, que não se opõe à formação geral, mas que a completa e viceversa.

Assim, uma proposta que deve ser discutida entre os profissionais da educação em torno da elaboração e sistematização de um currículo integrado é saber o que cada um dos conhecimentos (geral e especifico/profissional) propõe e como é possível a materialização dos mesmos em atividades didáticas integradoras ou, como denomina a autora, em ações didáticas integradoras, sempre com vistas à superação da fragmentação dos conteúdos e também que tais conteúdos sejam integrados à vida do aluno, ao seu fazer social, político e cultural, e não apenas educacional.

Pensar em pressupostos para a implementação de um currículo integrado requer ações integradoras concretas. Num terceiro movimento de nosso texto, apontamos que uma das propostas que têm sido satisfatórias dentro desse contexto de currículo integrado e que tem se concretizado em alguns Institutos Federais de Educação, Ciência e Tecnologia são os chamados "projetos integradores", os quais têm como proposta trabalhar de forma integrada e em equipe. Os alunos-pesquisadores devem elaborar e aplicar um projeto sob orientação dos professores de várias disciplinas.

Tal projeto (e demais projetos que podem assumir uma postura investigativa, criativa e crítica dentro dessa pedagogia integradora) possibilita a relação teoria e prática, a integração entre várias áreas do conhecimento com vistas a apresentar uma proposta que traga um retorno à comunidade local. Essa proposta insere o aluno na questão da transformação social, para a qual ele deve estar apto, a partir do conhecimento adquirido na escola de forma sistemática.

Nessa perspectiva, Machado (2010, p. 88) comenta:

Os projetos pedagógicos de concepção e implementação de currículos integrados podem encontrar boas aspirações em processos didáticos que objetivem agregar as informações do contexto ao processo de ensino aprendizagem. É preciso, entretanto, discutir como elas seriam trabalhadas e reestruturadas, tendo em vista a produção das conexões necessárias. Trata-se de tomar estas informações do contexto e da prática vivida, sistematizá-las com a 
ajuda dos conhecimentos disponíveis e pensar em alternativas de transformação de realidade.

Tratando dessa visão específica da organização de um currículo integrado, Ramos (2010) discute um projeto pedagógico de integração dos eixos trabalho, ciência e cultura na formação geral e profissional. Aponta alguns pressupostos norteadores e também desafiantes para professores e alunos que, de certa forma, reforça algumas questões até aqui ponderadas e outras novas.

Os estudantes são sujeitos histórico-sociais capazes de transformar a sociedade em que vivem; o processo de ensino-aprendizagem aponta para a formação humana e para a formação para o trabalho; o trabalho é entendido como princípio educativo, que compreende o significado histórico, social, econômico, político das artes e das ciências; os conteúdos são epistemologicamente trabalhados de forma a integrar conhecimentos gerais e conhecimentos específicos, tendo uma metodologia de ensino-aprendizagem que trabalhe as especificidades dos conhecimentos no que se refere à historicidade, finalidade e potencialidade dos mesmos; os conhecimentos gerais e específicos precisam ser construídos conjuntamente; a formação profissional não se restringe à operacionalização de uma técnica, se fundamentam nos processos científico-tecnológicos, sócio históricos e culturais tanto da produção em geral quanto da área específica; por último, pondera sobre a compreensão histórica da área específica e suas contradições como uma parte de um todo da produção material (RAMOS, 2010).

Essa educação ou formação integral configura-se em um ensino que abrange todas as dimensões da vida. Essa formação, ancorada em um currículo e práticas integradoras, proporcionará aos estudantes o pleno exercício da profissão como profissionais completos, dotando-os da capacidade de dirigir e não apenas de ser dirigidos, tendo também como alcance a perspectiva de uma formação humanística.

\section{UM OLHAR SOBRE A PESQUISA "LICENCIADOS, BACHARÉIS E A FORMAÇÃO DOCENTE PARA ATUAR NA EPT: A VOZ DOS PROFESSORES SOBRE A FORMAÇÃO INTEGRAL E INTEGRADA}

A pesquisa "Licenciados, bacharéis e a formação docente para atuar na EPT: um estudo com docentes do curso de informática no IFRN" aponta algumas informações relevantes para que possamos entender como os professores do ensino médio integrado do IFRN compreendem a formação integrada. Estes professores, conforme o título da pesquisa, são docentes do curso de nível médio integrado de informática dos campi Natal Central, Parnamirim e Natal Zona Norte. 0 curso de informática foi escolhido por ser ofertado em todos esses campi, o que permitiu um olhar mais homogêneo na pesquisa quanto ao extrato da formação docente.

Nosso estudo teve como instrumento de pesquisa a entrevista semiestruturada, cuja condução se reportou para as "Concepções sobre a EPT", visando conhecer a concepção de formação integral, formação integrada e a relação entre o ensino ofertado no IFRN e o mundo do trabalho. No entanto, nossa análise se deteve na concepção de formação integral e formação integrada. Para tanto, nos reportamos aos tipos de ensino ofertados. 
De acordo com o PPP /2012- IFRN, são ofertadas três formas de cursos técnicos - o Integrado Regular, o Integrado na modalidade de Educação de Jovens e Adultos e o Subsequente. A forma "integrado regular" se refere aos cursos do EMIEP, e é sobre esta modalidade que iremos tratar em nosso estudo.

Este projeto se constitui numa proposta de currículo integrado, na qual as disciplinas que fazem parte da matriz curricular dos cursos de nível médio integrado devem ser trabalhadas de forma articulada e fundamentar-se na interdisciplinaridade e na contextualização, buscando uma formação integrada que entrelaça ciência, trabalho, cultura e tecnologia, contribuindo, desse modo, para uma formação técnico-humanística sólida.

A integração curricular consiste, entre outros aspectos e pressupostos que orientam essa integração, nas práticas pedagógicas que precisam ser integradoras e buscar a articulação didática entre as disciplinas de formação geral e as disciplinas de formação profissional. Nessa perspectiva, a formação omnilateral, politécnica almejada pelo IFRN perpassa um ensino que se organiza na ministração das disciplinas de acordo com os núcleos estruturante, articulador e tecnológico.

Cabe-nos, a partir das considerações já apresentadas, fazer alguns questionamentos: qual a concepção de formação integrada dos professores de informática? Esses professores conhecem a concepção defendida no PPP do instituto onde trabalham? As concepções dos professores divergem ou convergem em relação à concepção discutida no PPP da instituição?

Para uma maior clareza acerca das siglas utilizadas para identificação dos sujeitos pesquisados e suas falas, apresentamos um quadro com sua respectiva significação:

\section{Quadro 2 - Siglas utilizadas para identificação das falas dos entrevistados}

\begin{tabular}{|l|c|}
\hline SIGLA ADOTADA & SIGNIFICADO \\
\hline P1/P2/P3 & \\
NE & Professor 1, professor 2, professor 3 \\
NA & Núcleo Estruturante \\
NT & Núcleo Articulador \\
CNAT & Núcleo Tecnológico \\
ZN & Campus Natal Central \\
PA & Campus Natal- Zona Norte \\
\hline
\end{tabular}

Fonte: autoria própria (2015).

Como corroboração à análise apresentada na parte conclusiva deste estudo, são apresentadas algumas falas dos docentes que permitirão uma visão geral do quantitativo de concepções sobre a formação integral e a formação integrada apresentada pelos vinte e sete professores entrevistados.

Em linhas gerais, independente do campus em que o professor atua, houve uma convergência de entendimentos e desentendimentos a respeito das concepções em foco. Outro fator apresentado diz respeito ao núcleo em que o docente pertence - os docentes dos núcleos 
estruturante e do articulador apresentam um discurso conceitual mais elaborado, e sinalizam a dificuldade de aproximação com as áreas técnicas; aos do núcleo tecnológico, compreendem a necessidade, exaltam a dificuldade e demonstram pouca crença na concretização do processo de formação integral e integrada.

Outro ponto apresentado por um grande percentual dos entrevistados, é a concordância de que a proposta de formação integral e integrada "existe no papel", ainda distante da prática. Os professores apontam a inexistência de diálogos sistematizados entre os docentes dos diversos componentes curriculares:

P2-NE-CNAT: "Bom... a minha concepção de formação integrada é esse modelo que é implantado no instituto em que existe uma integração pelo menos na grade curricular entre as disciplinas da formação propedêutica e das disciplinas técnicas... E na minha concepção só fica aí... na prática não existe uma integração tá só no documento".

P2-NE-ZN: "Mas eu vou confessar a você que eu não pontuo nas obras isso acontece naturalmente mas eu não trabalho especificamente isso eu trabalho a essência da obra pra formação deles... A gente tenta constantemente mas a gente não consegue interligar as disciplinas... Eu acho que a proposta existe no papel. Mas efetivamente a gente não tem essa educação integrada até porque as disciplinas propedêuticas elas às vezes são rechaçadas pela equipe técnica pelos técnicos são menos importantes... os meninos fazem teatro aqui e eles que fazem teatro, têm uma percepção e nem por isso eles deixam de ir lá, mexer nos circuitos, deixam de ir lá construir softwares, nada, entendeu? Então... é importantíssimo... Acontece naturalmente".

Os professores demonstram uma contradição na prática pedagógica existente no instituto no que se refere ao que está no PPP e ao que na prática deveria acontecer. O professor do Campus Natal Zona Norte utiliza o termo "interligar", mas demonstra que ainda não há uma compreensão de "integração". Compreende a integração como algo que ocorre "naturalmente" e não didaticamente. Sua fala deixa implícito que alguns professores entendem equivocadamente suas disciplinas como mais importantes do que outras, evidenciado uma hierarquização das áreas do conhecimento.

Já na percepção de outro entrevistado, há um esforço do IFRN para que essa formação seja efetivada, embora ainda não seja percebido o mesmo esforço junto aos docentes.

P3-NA-ZN: "É eu percebo que há muita vontade institucional de que haja a integração, mas potencialmente deixados às suas espontaneidades, esses conteúdos, não só da sociologia, mas das humanidades em geral, numa escola técnica, eles potencialmente são conflituosos eles não são integradores... Há o esforço institucional de misturar isso, de transformar isso em solução, mas o cotidiano é conflituoso, é de disputa. A gente vê nos alunos aqui um apego que eles têm por professor $X$, não tem com $Y$, né, na dedicação a uma matéria não tem com outra, e isso acontece muito, né, então, eu vejo um esforço institucional de integrar cursos, mas uma prática desintegradora".

Reforça-se aqui a questão da hierarquização das áreas do conhecimento ao citar um "cotidiano conflituoso" entre os professores das diferentes áreas, e também a preferência dos 
alunos por determinado componente curricular, afetando a relação entre aluno e professor, contribuindo também para o que chama "desintegração".

Em outros depoimentos, os professores discorrem sobre a formação humana:

P3-NE-CNAT: "[...] eu acho que a formação integrada é ter um homem de caráter um homem que tenha uma concepção de mundo que pode ser bom, que pode ser justo... é essa pessoa, acho que isso a gente alcança aqui".

Apesar de não ter o enfoque consolidado sobre a formação integrada, o professor acredita que o IFRN tem formado pessoas íntegras. Segue na mesma linha de pensamento o depoimento de outro professor:

P2-NA-CNAT: "[...] essa formação integrada, no meu entendimento, certo? É a somatória de tudo que a gente falou há pouco, né, o que eu aprendo enquanto ser humano, o que eu aprendo enquanto profissional... só".

Ao enfatizar "no meu entendimento", percebe-se a falta de uma fundamentação teórica mais embasada sobre a formação integrada, baseando-se em uma concepção mais do senso comum. Muito embora, o professor entenda que esta é uma formação de caráter humanista e profissional.

O trecho de outro professor denota maior compreensão epistemológica quando comenta a formação integral do sujeito:

P2-NE-PA: “Formação integral eu compreendo como... o próprio documento fala, o termo omnilateral, a amplitude do ser humano... e que nós somos constituídos de várias esferas. Então eu compreendo que formação integral é essa formação que vai além da formação técnica. A formação em que o indivíduo, o aluno, ele tenha a capacidade de se relacionar bem com outras pessoas, que ele possa lidar com suas dificuldades, seus medos, suas limitações, e.. para além do domínio técnico das disciplinas, dos conteúdos escolares, do que a gente chama de currículo tradicional".

Em sua fala, o professor demonstra conhecer o PPP e como lá é tratada a omnilateralidade. Sobre formação integrada, diz:

P2-NE-PA: “Na minha compreensão... uma formação integrada seria uma formação que não houvesse distinção entre formação técnica e formação humana... formação... essa formação humana mesmo... é tudo caminhando junto não só também as disciplinas técnicas, mas também as disciplinas gerais... essa formação que pudesse integrar todos esses saberes num contexto de ensino e aprendizado... Na minha concepção, seria mais ou menos isso".

Para este professor, a formação humana e a formação técnica devem "caminhar juntas" e integrar os saberes em um contexto de ensino-aprendizagem. Denotando, mais uma vez, um contexto de integração.

Outra percepção traz a sua concepção sobre como o aluno é preparado para dar continuidade aos estudos, citando a entrada do aluno na UFRN. No entanto, esse não é o foco principal da formação integrada. 
P3-NE-PA: “Quando eu escuto 'o aluno do IF tem uma formação integral' eu acho que parte daquela questão integral dos conhecimentos da base das disciplinas técnicas do social de ser completo em termos não é só a escola aqui, que eu entendo a escola é muito mais, que escola porque você convive com o diferente o que você não acha legal você convive aqui, ninguém sabe quem é filho de quem... Aqui você é aluno e aluno de forma integral, você participa de tudo mesmo, então você sai mais maduro, você sai mais completo, eu acho..., pra encarar, por exemplo, uma UFRN".

Outro professor, não compreende, na formação profissional, o trabalho como um princípio educativo, mas como um "ofício:

P2-NT-PA: "Formação integral. Creio eu que seja um misto de você ter a experiência propedêutica, ter as disciplinas que vemos nas escolas que não são técnicas... e de ter essa formação para o ofício, como diz a linguagem mais antiga, ter o ofício daquela profissão que você escolheu. E aí você tem aquela integralização do conhecimento, você tem o ensino propedêutico e o ensino técnico".

Conceber o trabalho como um princípio educativo está além da formação para a instrumentalização, está ligado à formação para a sociedade e para a vida. Na fala desse professor, o foco é o mercado.

Este entendimento é também compartilhado na fala a seguir:

P2-NA-ZN: "Já a formação integrada é a que nós nos propormos a paralelo ao conteúdo técnico, ofertar um conteúdo propedêutico onde essa formação vai servir para esse aluno ingressar no mercado de trabalho ou verticalizar o seu ensino".

Diante das concepções acima apresentadas, fica evidenciado que devido à estrutura do campus Natal Central, há uma maior separação entre os núcleos, o que dificulta o diálogo entre os professores da formação geral e os docentes da formação técnica. Disso decorre, muitas vezes, uma separação ainda maior na didática de cada professor, pois, por não haver a interação entre os professores e a integração entre as disciplinas, muitas vezes ocorre uma sobreposição de disciplinas e a consequente fragmentação dos saberes.

\section{CONSIDERAÇÕES FINAIS}

Como um possível contributo à discussão de formação integral dos sujeitos da EP, ancorada em práticas formadoras integradas, o estudo confirmou alguns pressupostos da nossa pesquisa no que diz respeito à existência de uma grande lacuna entre o discurso posto, o escrito, o dito e o praticado.

Observou-se, durante a realização da pesquisa, que tais concepções, apesar de fazerem parte dos documentos institucionais, ainda não estão compreendidas epistemologicamente, como também não se materializaram no fazer cotidiano dos docentes pesquisados. Nesse sentido, compreendemos que essa contradição deva ser discutida e resolvida, de forma que a materialização do escrito seja efetivada de fato e de direito, não apenas como uma possibilidade, 
mas como viés único que permite aos sujeitos da EP se constituírem plenos, críticos e reflexivos perante uma sociedade desigual que nos é imposta pelo capitalismo vigente.

Assim sendo, realizar a integração entre as disciplinas torna-se um desafio, uma vez que é de grande relevância, para essa formação, que as disciplinas dialoguem e, mais ainda, que essas disciplinas trabalhem de modo efetivo a formação humana nos futuros técnicos em formação e ajudem-nos a compreender e se perceber cidadãos-trabalhadores éticos e comprometidos eticamente com suas profissões, bem como com a sociedade em geral.

Para tanto, é necessário que os professores do IFRN conheçam as concepções e pressupostos da formação integrada defendidas no PPP. Esse conhecimento os auxiliará a entender o que significa a formação integrada e a própria proposta de currículo integrado para, então, trabalhar sobre este currículo.

É necessário que enquanto educadores que somos, possamos praticar a utopia necessária para confrontar e combater uma formação engessada, mutilada, restrita e unilateral. Desta forma, cabe à instituição promover cursos de qualificação e aperfeiçoamento presenciais ou a distância que promovam a compreensão dos docentes e a apropriação do conceito em sua prática.

\section{REFERÊNCIAS BIBLIOGRÁFICAS}

1. BRASIL. Lei no 9.394, de 20 de dezembro de 1996. Estabelece as diretrizes e bases da educação nacional. Disponível em:< http://www.planalto.gov.br/ccivil_03/leis/ 19394.htm>. Acesso em: 5 out. 2014.

2. CIAVATTA, Maria. A formação integrada: a escola e o trabalho como lugares de memória e de identidade. In. FRIGOTTO, G.; CIAVATTA, M.; RAMOS, M. (Org.). Ensino médio integrado: concepções e contradições. São Paulo: Cortez, 2005. p. 83-105.

3. IMBERNÓN, Francisco. A necessária redefinição da docência como profissão. In:

Formação docente e profissional: formar-se para a mudança e a incerteza. 9 ed. São Paulo: Cortez, 2011, p. $11-19$.

4.

O debate sobre a profissionalização docente In: .9 ed. São Paulo: Cortez, 2011, p. 25 a 29.

5. INSTITUTO FEDERAL DO RIO GRANDE DO NORTE. Projeto Político-Pedagógico do IFRN: uma construção coletiva. Natal: Editora do IFRN, 2012.

6. MACHADO, Lucilia Regina de Souza. O desafio da formação dos professores para a ept e proeja. Revista Educ. Soc., Campinas, v. 32, n. 116, p. 689-704, jul.-set. 2011. Disponível em:< http://www.cedes.unicamp.br>. Acesso em: 20 mar. 2015.

7. _ _ Formação de professores para a educação profissional tecnológica: perspectivas históricas e desafios contemporâneos. In: MOURA, Dante Henrique (Org.). Produção de conhecimento, políticas públicas e formação docente em educação profissional. Campinas, SP: Mercado das Letras, 2013, p.347-361.

8. __ Ensino médio e técnico integrado com currículos integrados: propostas de ação didática para uma relação não fantasiosa. In: MOLL, Jaqueline et al. Educação profissional e 
tecnológica no Brasil contemporâneo: desafios, tensões e possibilidades. Porto Alegre: Artmed, 2010. p. 80-95.

9. MOLL, Jaqueline et al. Educação profissional e tecnológica no Brasil contemporaneo: desafios, tensões e possibilidades. Porto Alegre: Artmed, 2010.

10. MOURA, Dante Henrique (Org.). Produção de conhecimento, políticas públicas e formação docente em educação profissional. Campinas, SP: Mercado de Letras, 2013.

11. MINAYO, Maria Cecília de Souza. O desafio do conhecimento: pesquisa qualitativa em saúde. 8 ed. São Paulo: Hucitec, 2004.

12. RAMOS, Marise. Ensino médio integrado: ciência, trabalho e cultura na relação entre educação profissional e educação básica. In: MOLL, Jaqueline et al. Educação profissional e tecnológica no Brasil contemporâneo: desafios, tensões e possibilidades. Porto Alegre: Artmed, 2010. p. 42-57.

13. _. Possibilidades e desafios na organização do currículo integrado. In: FRIGOTTO, G.; CIAVATTA, M.; RAMOS, M. (Org.). Ensino médio integrado: concepções e contradições. São Paulo: Cortez, 2005. p.106-127.

14. URBANETZ, Sandra Terezinha. Uma ilustre desconhecida: a formação docente para a educação profissional - Tese. Rev. Diálogo Educ., Curitiba, v. 12, n. 37, p. 863-883, set./dez. 2012. 